\title{
ANTIMICROBIAL PROPERTIES OF BUTANOLAMINES AND PROPANOLAMINES IN METAL WORKING FLUIDS
}

\author{
E. O. BENNETT, M. C. ADAMS, AND G. TAVANA \\ Department of Biology, University of Houston, \\ Houston, Texas 77004, U.S.A.
}

(Received July 3, 1978)

\begin{abstract}
Seventeen propanolamines, six diisopropanolamines, and two butanolamines were studied for their antimicrobial properties against a mixed flora of fungi and bacteria in cutting fluids. All of the propanolamines showed inhibitory properties in the lubricants. Isopropanolamines were found to have very weak antimicrobial properties, and both butanolamine compounds were inhibitory. The most active compound found was L-2-methylamino-1-phenolpropanol, but other chemicals including DL-2-benzylamino-1-propanol, 3-diethylamino-1-propanol, 2-amino-2methyl-1-propanol, 2-dimethylamino-2-methyl-1-propanol, 1-dimethylamino-3-propanol, and 3-amino-1-propanol all showed good antimicrobial properties in the products.
\end{abstract}

Specialized lubricants which contain oil-in-water or water-in-oil systems are commonly used by industry. Unfortunately, there are two problems which may be encountered with these types of products. First, due to the fact that they are emulsions, they are subject to biodeterioration while in use. For this reason, they usually require the addition of some type of antimicrobial agent at periodic intervals. Second, due to the presence of water, they must contain a corrosion inhibitor in order to prevent damage to metals.

The most common corrosion inhibitor employed in these products has been sodium nitrite. However, the presence of this chemical may result in the production of carcinogenic nitrosoamines in these lubricants (l). Since this information has become available, there has been interest in developing substitutes for sodium nitrite that can be used in these products.

Unfortunately, the substitution of other corrosion inhibitors has resulted in a major cost increase since no comparable corrosion inhibitor can compete favorably with sodium nitrite from the cost standpoint. In order to minimize costs, it would be of considerable value if these lubricants could be formulated with in- 
gredients which have different functions within the products. Antimicrobial agents and corrosion inhibitors constitute two important components of these lubricants. It would be of interest then to search for chemicals that can function both as corrosion inhibitors as well as antimicrobial agents.

The concept of employing a compound that functions in both capacities in a lubricant is not new. More than 20 years ago, the use of 2, 5-dimercapto-1, 3, 4thiadiazole was suggested for use as a corrosion inhibitor and preservative for cutting fluids (2). Several years later, other workers studied the antimicrobial properties of several corrosion inhibitors with negative results (3). Potassium tetraborate has been suggested for use in cutting fluids because it exhibits both properties (4). More recently, amine salts of boric acid-polyol complexes have been found to inhibit pseudomonads and sulfate-reducing bacteria while at the same time producing corrosion protection of mild steel plates (5), chromates have been employed to control both corrosion and microorganism (6), and several piperazine compounds have been produced which exhibit both properties as well as cooling, lubricating, and cleaning properties (7).

In a previous communication (8), the antimicrobial properties of 59 monoethanolamines, diethanolamines, and triethanolamines in cutting fluids were reported. In addition, this paper reviewed what is known pertaining to the properties of aminoalcohols in regards to their physical and chemical properties as well as their uses, toxicity, and their effect upon the environment. Those interested in these subjects should consult the previous publication.

The objective of this investigation was to determine, the antimicrobial properties of propanolamines, isopropanolamines and butanolamines in cutting fluids.

\section{MATERIALS AND METHODS}

All of the compounds employed in this investigation were 95 to $99 \%$ pure and were obtained from a number of chemical specialty supply houses.

The test units consisted of quart jars placed in rows. Above each row a metal framework was constructed to support the aeration system which consisted of aquarium valves connected together with plastic tubing. The amount of aeration of each unit was controlled by adjusting the valves. Capillary pipettes were employed as aerators to produce a fine stream of bubbles in the diluted coolants.

Five hundred $\mathrm{ml}$ of tap water (moderate hardness) was added to each jar. Each compound was used as obtained from the manufacturer and the required concentration (w/v or v/v) was added to each unit along with $15.0 \mathrm{ml}$ of coolant concentrate to produce the desired oil-water ratio. Each unit was then made up to a total volume of $600.0 \mathrm{ml}$ by adding additional tap water.

Each test unit was inoculated with a mixture of bacteria and molds which were obtained and maintained as described previously (9). Each unit was inoculated once each week with $1.0 \mathrm{ml}$ of a $50-50$ mixture of both inocula. 
Each unit was examined once each week for its microbial content for as long as the count remained below 100,000 organisms $/ \mathrm{ml}$. Two consecutive counts in excess of this figure at weekly intervals was considered to constitute a failure and the test was discontinued at that time. In addition, all units which contained less than 100,000 organisms/ml were studied for a 105-day test period and discarded at that time.

Two different types of control experiments were included with all tests. Each shipment of fresh coolant was tested upon arrival in this laboratory to determine if the product exhibited any inhibitory properties as defined in the previous paragraph. All of the coolants used in the investigation were especially prepared by coolant manufacturers for this work and they did not contain a preservative. None of the products employed in this investigation exhibited any inhibitory properties and failed in the first week of testing. Since this communication constitutes a continuation of past work by this laboratory in regard to cutting fluid deterioration, an additional set of controls (4 test units) were included. It may be noted that the inoculum employed was a mixture of microorganisms and constitutes a dynamic system susceptible to changes in sensitivity of the organisms to antimicrobial agents. The second set of controls consisted of a particular cutting fluid preserved with a commonly used cutting fluid preservative. Normally, these control units fail in 21 to 28 days due to mold growth and have done so for the past several years. These controls functioned normally during the test period.

Since the test units were under constant aeration, there was considerable evaporation from each unit. The units were calibrated at the $600.0 \mathrm{ml}$ mark and, once or twice each week depending on environmental conditions, distilled water was added to each unit to bring the liquid level back to this mark. Distilled water was used in order to avoid a buildup of inorganic salts in the test units.

\section{RESULTS}

Table 1 exhibits the results of a study of the antimicrobial properties of propanolamines in cutting fluids. It may be noted that this group of compounds showed a preservative action in most of the fluids in the study. The most active chemical was L-2-methylamino-1-phenylpropanol, but, other compounds including DL-2-benzylamino-1-propanol, 3-diethylamino-1-propanol, 2-amino-2-methyl1-propanol, 2-dimethylamino-2-methyl-1-propanol, 1-dimethylamino-3-propanol, and 3-amino-1-propanol all inhibited the mixed microbial flora. It was noted that there was a marked tendency for mold deterioration in the cutting fluids treated with 3-amino-1-propanol and 2-amino-2-methyl-1-propanol.

Table 2 exhibits data concerning the antimicrobial properties of several isopropanolamines. This group of chemicals exhibited less preservative activity than did the propanolamines. Isopropanolamine was the only compound with 


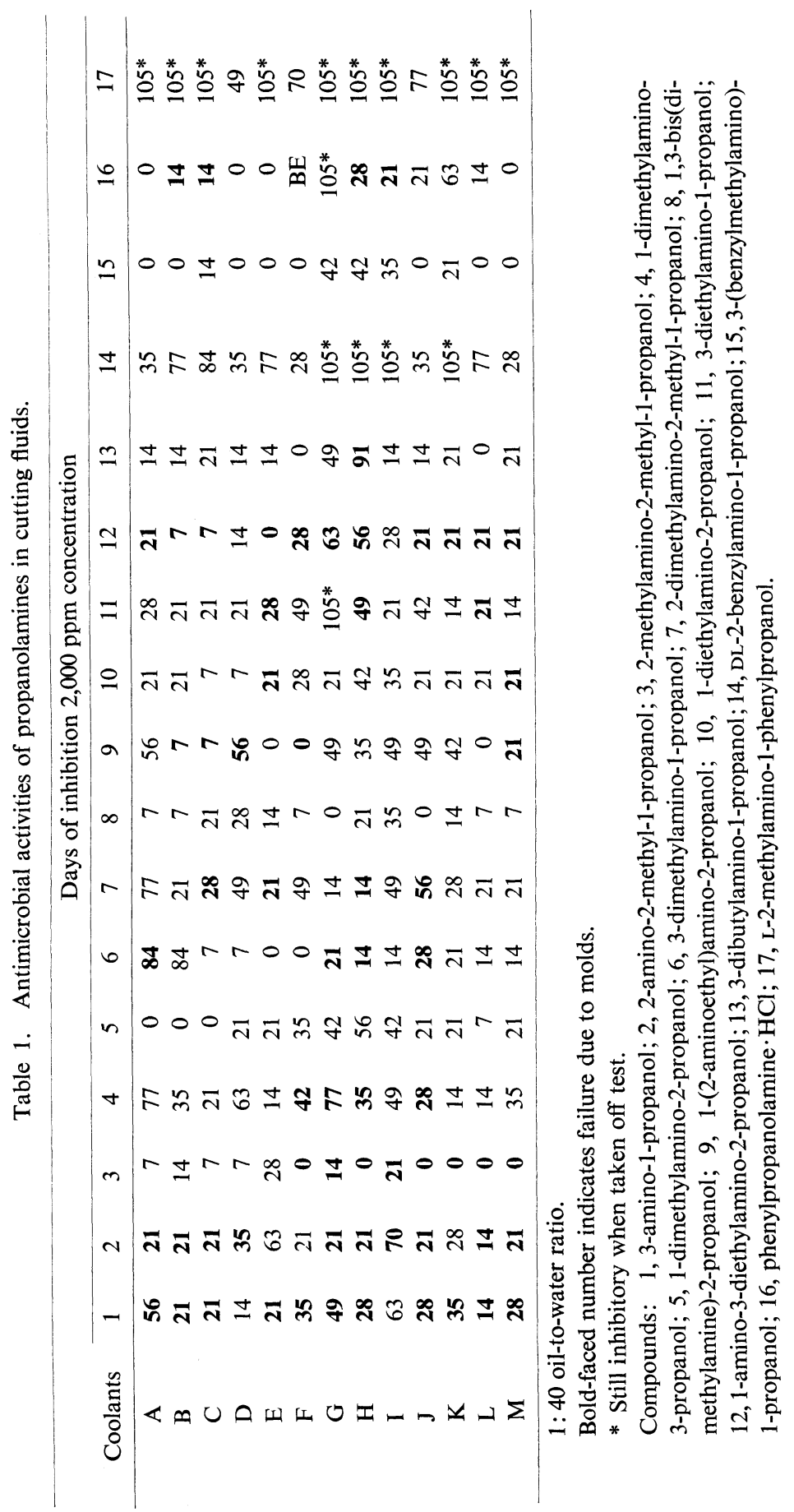


Table 2. Antimicrobial activities of isopropanolamines in cutting fluids.

\begin{tabular}{lcccrrr}
\hline \multirow{2}{*}{ Coolants } & \multicolumn{7}{c}{ Days of inhibition 2,000 ppm concentration } \\
\cline { 2 - 6 } & 1 & 2 & 3 & 4 & 5 & 6 \\
\hline A & 42 & 21 & 0 & 0 & 0 & 0 \\
B & 35 & 28 & 0 & $\mathbf{2 1}$ & 0 & 0 \\
C & 28 & 21 & 0 & 0 & 0 & 0 \\
D & 35 & 28 & 0 & 0 & 0 & 0 \\
E & 35 & 21 & 0 & 0 & 0 & 0 \\
F & 70 & $\mathbf{6 3}$ & 0 & 0 & 14 & 0 \\
G & 42 & 35 & 0 & $\mathbf{7 0}$ & 21 & 21 \\
H & 56 & 42 & 0 & 28 & $\mathbf{2 1}$ & 0 \\
I & 49 & 35 & 0 & 42 & 14 & 0 \\
J & 42 & 28 & 0 & 0 & 0 & 0 \\
K & 42 & 28 & 0 & 0 & 0 & 0 \\
L & 21 & 21 & 0 & $\mathbf{1 4}$ & $\mathbf{0}$ & $\mathbf{0}$ \\
M & 28 & 21 & 0 & 0 & 0 & 0 \\
\hline I & & & 0 & & 0 \\
\hline
\end{tabular}

$1: 40$ oil-to-water ratio.

Bold-faced number indicates failure due to molds.

Compounds: 1, isopropanolamine; 2, N, N-dimethyl isopropanolamine; 3, isopropanolamine oleate; 4 , diisopropanolamine; 5 , N-butyl diisopropanolamine; 6 , triisopropanolamine.

Table 3. Antimicrobial activities of butanolamines in cutting fluids.

\begin{tabular}{ccc}
\hline & \multicolumn{2}{c}{ Days of inhibition 2,000 ppm concentration } \\
\cline { 2 - 3 } Coolants & 1 & 2 \\
\hline A & $\mathbf{1 4}$ & $\mathbf{2 1}$ \\
B & 21 & 21 \\
C & 21 & 35 \\
D & 14 & 42 \\
E & 28 & 14 \\
F & 21 & 28 \\
G & 49 & $105 *$ \\
H & 21 & 35 \\
I & 21 & 35 \\
J & 0 & 28 \\
K & 35 & 49 \\
L & 0 & 28 \\
M & 14 & 28 \\
\hline
\end{tabular}

$1: 4$ oil-to-water ratio.

Bold-faced number indicates failure due to molds.

* Still inhibitory when taken off test.

Compounds: 1, 2-amino-1-butanol; 2, 2-amino-3-methyl-1-butanol. 
significant inhibitory properties.

Table 3 shows the antimicrobial properties of two aminobutanol compounds. While both show activity, 2-amino-3-methyl-1-butanol was the best compound of the two studied.

Almost without exception, the compounds markedly improved emulsion stability by facilitating the mixing and production of smooth tight emulsions, and several products noted for their emulsion instability lost this quality when these chemicals were added to them.

\section{DISCUSSION}

Propanolamines have been suggested for use in metal working fluids by several workers. In one patent (4) 2-amino-2-methyl-1-propanol was employed as an antifoam agent in coolants. A later patent (10) specified the use of triisopropanolamine, diisopropanolamine, and isopropanolamine in cutting fluids to impart antirust properties and lubricity to the formulations. A third patent (11) discussed the use of 2-amino-2-methyl-1-propanol, 2-amino-2-ethyl-1-propanol, or 2-amino-1-propanol as anticorrosion components for these lubricants.

Propanolamines and butanolamines are known to exhibit antimicrobial properties in cutting fluids. It has been reported that 2-amino-1-butanol (12) and $\mathrm{N}$-(2-nitrobutyl)-1-amino-2-propanol (13) were effective cutting fluid preservatives. The present investigation confirms that 2-amino-1-butanol does indeed exhibt antimicrobial activity. However, it is apparent that there are more active compounds within the group of propanolamines and butanolamines than this compound.

Propanolamines and butanolamines exhibit significant antimicrobial properties when added to these specialized lubricants. In addition, careful study of the tables indicates some important possibilities as to the synthesis of new compounds which can be expected to exhibit perhaps even better inhibitory properties.

When all of the alcoholamines shown in both communications are compared, it is evident that propanolamines exhibit the greatest antimicrobial activities, that ethanolamines exhibit weaker inhibitory properties although they are significant, and that other groups exhibit even weaker properties. No conclusions in this regard can be made for the butanolamines as only two compounds could be obtained for study.

The use of such chemicals in conjunction with glycols and other coolant components that exhibit antimicrobial properites could possibly result in the development of cutting fluids that offer rancidity control without the requirement of using an antimicrobial agent to accomplish this goal. This could result in lower costs of producing such lubricants and reduce adverse environmental effects.

Acknowledgements. Abbott Laboratories, North Chicago, Illinois; Applied Chemicals, Pty. Ltd., Melbourne, Australia; Anderson Oil \& Chemical Company, Inc., Portland, Connecticut; 
Ashland, Inc., Ashland, Kentucky; Bellucco \& Co., S.A.S., Torino, Italy; Blaser CO AG, Switzerland; Buckeye Lubricants, Bedford, Ohio; D. A. Stuart Oil Company, Chicago, Illinois; De Mille Chemical Corporation, Jersey City, New Jersey; Dow Chemical Company, Midland, Michigan; Glyco Chemicals, Inc., Williamsport, Pennsylvania; Henry E. Sanson \& Sons, Inc., Bristol, Pennsylvania; International Chemical Company, Philadelphia, Pennsylvania; IMC Chemical Group, Terre Haute, Indiana; International Refining \& Manufacturing Co., Evanston, Illinois; Lehn \& Fink Products Co., Montvale, New Jersey; Monroe Chemical Company, Inc., Hilton, New York; Norton Company, Worcester, Massachusetts; Olin Corporation, New Haven, Connecticut; Onyx Chemical Company, Jersey City, New Jersey; Polar Chip, Inc., Irvine, California; Quaker Chemical Corporation, Conshohocken, Pennsylvania; Reynolds Metals Company, Richmond, Virginia; Rohm and Hass Company, Philadelphia, Pennsylvania; S. C. Johnson \& Son, Inc., Racine, Wisconsin; S. H. Mack and Company, Inc., Aurora, Illinois; Shell Oil Company, Houston, Texas; Sun Oil Company, Marcus Hook, Pennsylvania; Tapmatic Corporation, Irvine, California; Tower Oil \& Technology Company, Chicago, Illinois; Union Carbide Corporation, Tarrytown, New York; Union Oil Company of California, Brea, California; Van Straaten Chemical Company, Chicago, Illinois.

\section{REFERENCES}

1) W. LiJinsky and S. S. Epstein, Nature (London), 225, 21 (1970).

2) E. N. Roberts and E. K. Fields, U.S. Patent 2,703,785 (March, 1955).

3) D. G. Lundgren and A. Krikszens, Appl. Microbiol., 7, 292 (1959).

4) C. A. Sluhan, U.S. Patent 2,999,064 (September, 1961).

5) L. W. Jones, U.S. Patent No. 3,373,170 (1968).

6) W. P. Iverson, Corros. Prev. Control, 16, 15 (1969).

7) D. Schuster, Ger. Patent 1,620,447 (1975).

8) E. O. Bennett, Lubr. Eng., 35, 137 (1978).

9) E. O. Bennett, Prog. Ind. Microbiol., 16, 119 (1974).

10) W. R. Siegart, N. R. Odell, and W. V. Taylor, U.S. Patent 3,180,830 (April, 1965).

11) R. L. Quanstrom, U.S. Patent 3,201,349 (August, 1965).

12) E. O. BennetT and H. N. Futch, Lubr. Eng., 16, 228 (1960).

13) E. B. Hodge, U.S. Patent 3,183,189 (1965). 